\title{
MODELLING MATRIX MULTI-CRACKING EVOLUTION OF FIBRE-REINFORCED CERAMIC-MATRIX COMPOSITES CONSIDERING FIBRE FRACTURE
}

\author{
LI LONGBIAO \\ College of Civil Aviation, Nanjing University of Aeronautics and Astronautics \\ No.29 Yudao St., Nanjing 210016, PR China \\ E-mail: 1lb451@nuaa.edu.cn
}

Submitted May 1, 2018; accepted July 17, 2018

\begin{abstract}
Keywords: Ceramic-matrix composites (CMCs), Matrix multi-cracking, Interface debonding, Fibre fracture
In this paper, the matrix multi-cracking evolution of fibre-reinforced ceramic-matrix composites (CMCs) considering fibre fracture have been investigated using the critical matrix strain energy criterion. The shear-lag model combined with the fibre fracture model and fibre/matrix interface debonding criterion is adopted to analyse the fibre and matrix axial stress distribution inside the damaged composite. The effects of the fibre volume fraction, the fibre/matrix interface shear stress, the fibre/matrix interface debonded energy, the fibre Weibull modulus and the fibre strength on the stress-dependent matrix multi-cracking development are discussed. The experimental matrix multi-cracking evolution of the unidirectional SiC/CAS, $\mathrm{SiC} / \mathrm{CAS}$-II, SiC/SiC, SiC/Borosilicate and mini-SiC/SiC composites are predicted.
\end{abstract}

\section{INTRODUCTION}

Ceramic materials possess high specific strength and specific modulus at elevated temperatures. But their use as structural components is severely limited because of their brittleness. Continuous fibre-reinforced ceramic-matrix composites (CMCs), by incorporating fibres in ceramic matrices, not only exploit their attractive high-temperature strength, but also reduce the propensity for catastrophic failure [1,2]. These materials have already been implemented on some aero engine components [3]. The environment inside the hot section of the components is harsh and a composite is typically subjected to complex thermomechanical loading, which can lead to matrix multi-cracking $[4,5]$. These matrix cracks form paths for the ingress in the environment oxidising the fibres and leading to premature failure [6-9]. The density and openings of these cracks depend on the fibre architecture, the fibre/matrix interface bonding intensity and the applied load [10]. It is important to develop an understanding of the matrix multi-cracking damage mechanisms to analyse the oxidation behaviour inside of the CMCs. [11]

Many researchers performed experimental and theoretical investigations on the matrix multi-cracking evolution of fibre-reinforced CMCs. Pryce and Smith [12] investigated the quasi-static tensile behaviour of unidirectional and cross-ply SiC/calcium aluminosilicate (CAS) glass-ceramic composites. The first matrix cracking stress is predicted using the Aveston-CooperKelly (ACK) theory [13], and the relationship between the matrix cracking density and the stiffness reduction is analysed with an increasing strain. Beyerle et al. [14] investigated the mechanical characteristic of the unidirectional SiC/CAS-II composite, and the first matrix cracking stress and the composite ultimate strength are predicted using the micromechanical models. However, the evolution of the matrix multicracking and modulus reduction show a difference between the experimental data and theoretical analysis without considering the fibres failure. Holmes and Cho [15] investigated the effect of the matrix crack spacing on the surface temperature rising from the unidirectional $\mathrm{SiC} / \mathrm{CAS}-\mathrm{II}$ composite. It was found that the onset of frictional heating under cyclic loading coincides with the first matrix cracking stress, and the extent of frictional heating increases as the average matrix crack spacing decreases at a given fatigue peak stress and stress ratio. Okabe et al. [16] investigated the failure process of the unidirectional $\mathrm{SiC}$ /Borosilicate composite under tensile loading. The relationship between the matrix multi-cracking evolution and stress/ strain curve is analysed, and it is found that the first matrix cracking stress is close to the knee point of the 
nonlinearity in the tensile stress/strain curve. Smith et al. [17] investigated the damage accumulation in a $2 \mathrm{D}$ woven $\mathrm{SiC} / \mathrm{SiC}$ composite using electrical resistance. It was found that the resistance change in the $\mathrm{SiC} / \mathrm{SiC}$ composite is sensitive to matrix cracking [18]. Gowayed et al. [19] investigated the feasibility of utilising the shear-lag theory to estimate the matrix crack density in a fabric reinforced $2 \mathrm{D} \mathrm{SiC} / \mathrm{SiC}$ composite. The matrix cracking density was highly sensitive to fibre volume fraction along the loading direction and the fibre/matrix interface shear strength between the fibres and matrix. Ogasawara et al. [20] investigated the experimental matrix multi-cracking of an orthogonal 3D woven $\mathrm{Si}-\mathrm{Ti}-\mathrm{C}-\mathrm{O}$ fibre/Si-Ti-C-O matrix composite using microscopic observation. The inelastic tensile stress/ strain behaviour is governed by matrix multi-cracking in the transverse fibre bundles at a low stress, matrix multi-cracking in longitudinal fibre bundles at an intermediate stress, and fibre fragmentation at a high stress. Morscher et al. [21] investigated the occurrence of matrix cracks in a melt-infiltrated 3D orthogonal architecture $\mathrm{SiC} / \mathrm{SiC}$ composite under tension parallel to the Y-direction which is perpendicular to the Z-bundle weave direction using acoustic emissions (AE). The matrix cracking stress range depended upon the Z-direction bundle size and the local architecture. Solti et al. [22] developed an approach of a critical matrix strain energy (CMSE) criterion to analyse the matrix multicracking evolution, in which the maximum fibre/ matrix interface shear strength criterion was adopted to determine the interface debonded length during matrix multi-cracking. However, following the arguments of Gao et al. [23] and Stang and Shah [24], the fracture mechanics approach is preferred to the shear strength approach for the fibre/matrix interface debonding problem. Rajan and Zok [25] investigate the mechanics of a fully bridged steady-state matrix cracking in unidirectional CMCs under shear loading. The studies mentioned above, however, do not consider the effect of fibre debonding on the matrix multi-cracking evolution in fibre-reinforced CMCs.

In this paper, the matrix multi-cracking evolution of fibre-reinforced $\mathrm{CMCs}$ considering fibre fracture is investigated using the critical matrix strain energy criterion. The shear-lag model combined with the fibre fracture model and fibre matrix interface debonding criterion is adopted to analyse the fibre and matrix axial stress distribution inside the damaged composite. The effects of the fibre volume fraction, the fibre/matrix interface shear stress, the fibre/matrix interface debonded energy, the fibre Weibull modulus and the fibre strength on the stress-dependent matrix multi-cracking evolution are discussed. The experimental matrix multicracking evolution of the unidirectional $\mathrm{SiC} / \mathrm{CAS}, \mathrm{SiC} /$ CAS-II, SiC/SiC, SiC/Borosilicate and mini-SiC/SiC composites are predicted.

\section{THEORETICAL ANALYSIS}

Stress analysis

To analyse the stress distributions in the sand matrix of the damaged composite, a unit cell is extracted from the CMCs, as shown in Figure 1. The unit cell contains a single fibre surrounded by a hollow cylinder of the matrix. The fibre radius is $r_{\mathrm{f}}$, and the matrix radius is $R\left(R=r_{\mathrm{f}} / V_{\mathrm{f}}^{1 / 2}\right)$. The length of the unit cell is $l_{\mathrm{c}} / 2$, which is half of the matrix crack spacing. The fibre/ matrix interface debonded length is $l_{\mathrm{d}}$. At the matrix cracking plane, fibres carry all the stress $\left(\sigma / V_{\mathrm{f}}\right.$, where $\sigma$ denotes the far-field applied stress and $V_{f}$ denotes the fibre volume fraction). The shear-lag model adopted by Budiansky, Hutchinson and Evans [26] is obtained to perform the stress and strain calculations in the fibre/ matrix interface debonded region $\left(x \in\left[0, l_{\mathrm{d}}\right]\right)$ and interface bonded region $\left(x \in\left[l_{\mathrm{d}}, l_{\mathrm{c}} / 2\right]\right)$. The fibre axial stress $\sigma_{\mathrm{f}}(x)$, the matrix axial stress $\sigma_{\mathrm{m}}(x)$ and the fibre/matrix interface shear stress $\tau_{\mathrm{i}}(x)$ are determined using the following equations:

$\sigma_{\mathrm{f}}(x)=\left\{\begin{array}{l}T-\frac{2 \tau_{\mathrm{i}}}{r_{\mathrm{f}}} x, x \in\left(0, l_{\mathrm{d}}\right) \\ \sigma_{\mathrm{fo}}+\left(T-\sigma_{\mathrm{fo}}-2 \frac{l_{\mathrm{d}}}{r_{\mathrm{f}}} \tau_{\mathrm{i}}\right) \exp \left(-\rho \frac{x-l_{\mathrm{d}}}{r_{\mathrm{f}}}\right), x \in\left(l_{\mathrm{d}}, \frac{l_{\mathrm{c}}}{2}\right)\end{array}\right.$

$\sigma_{\mathrm{m}}(x)=\left\{\begin{array}{l}2 \frac{V_{\mathrm{f}} \tau_{\mathrm{i}}}{r_{\mathrm{f}} V_{\mathrm{m}}} x, x \in\left(0, l_{\mathrm{d}}\right) \\ \sigma_{\mathrm{mo}}-\frac{V_{\mathrm{f}}}{V_{\mathrm{m}}}\left(T-\sigma_{\mathrm{fo}}-2 \tau_{\mathrm{i}} \frac{l_{\mathrm{d}}}{r_{\mathrm{f}}}\right) \exp \left(-\rho \frac{x-l_{\mathrm{d}}}{r_{\mathrm{f}}}\right), x \in\left(l_{\mathrm{d}}, \frac{l_{\mathrm{c}}}{2}\right)\end{array}\right.$

$\tau_{\mathrm{i}}(x)=\left\{\begin{array}{l}\tau_{\mathrm{i}}, x \in\left(0, l_{\mathrm{d}}\right) \\ \frac{\rho}{2}\left(T-\sigma_{\mathrm{fo}}-2 \frac{l_{\mathrm{d}}}{r_{\mathrm{f}}} \tau_{\mathrm{i}}\right) \exp \left(-\rho \frac{x-l_{\mathrm{d}}}{r_{\mathrm{f}}}\right), x \in\left(l_{\mathrm{d}}, \frac{l_{\mathrm{c}}}{2}\right)\end{array}\right.$

where $T$ denotes the stress carried by the intact fibres; $V_{\mathrm{m}}$ denotes the matrix volume fraction; $\tau_{\mathrm{i}}$ denotes the fibre/matrix interface shear stress; $\rho$ denotes the shearlag model parameter; and $\sigma_{\mathrm{fo}}$ and $\sigma_{\mathrm{mo}}$ denote the fibre and matrix axial stress in the interface bonded region, respectively.

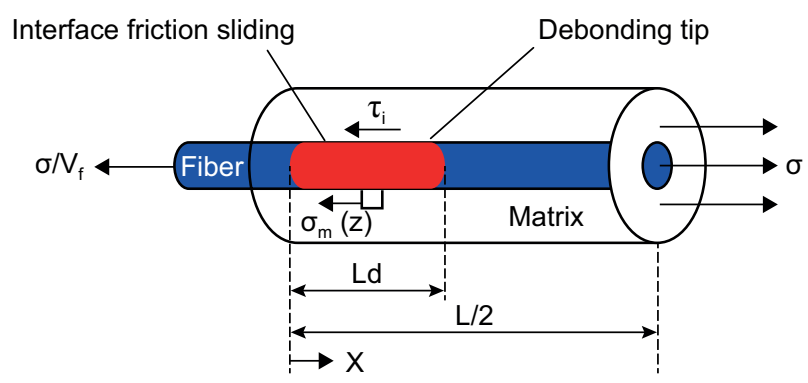

Figure 1. The material properties of the SiC/CAS, SiC/CASII, $\mathrm{SiC} / \mathrm{SiC}, \mathrm{SiC} /$ Borosilicate and the mini-SiC/SiC composites. 


$$
\begin{gathered}
\sigma_{\mathrm{fo}}=\frac{E_{\mathrm{f}}}{E_{\mathrm{c}}} \sigma+E_{\mathrm{f}}\left(\alpha_{\mathrm{c}}-\alpha_{\mathrm{f}}\right) \Delta \mathrm{T} \\
\sigma_{\mathrm{mo}}=\frac{E_{\mathrm{m}}}{E_{\mathrm{c}}} \sigma+E_{\mathrm{m}}\left(\alpha_{\mathrm{c}}-\alpha_{\mathrm{m}}\right) \Delta \mathrm{T}
\end{gathered}
$$

where $E_{\mathrm{f}}, E_{\mathrm{m}}$ and $E_{\mathrm{c}}$ denote the fibre, matrix and composite elastic modulus, respectively; $\alpha_{\mathrm{f}}, \alpha_{\mathrm{m}}$ and $\alpha_{\mathrm{c}}$ denote the fibre, matrix and composite thermal expansion coefficient, respectively; and $\Delta \mathrm{T}$ denotes the temperature difference between the fabricated temperature $\mathrm{T}_{0}$ and the testing temperature $\mathrm{T}_{1}\left(\Delta \mathrm{T}=\mathrm{T}_{1}-\mathrm{T}_{0}\right)$.

The possibility of fibre failure within the matrix due to the statistical nature of the fibre strength can be accounted for by using the Weibull analysis. The twoparameter Weibull model is adopted to describe the fibre strength distribution, and the Global Load Sharing (GLS) assumption is used to determine the stress carried by the intact and fracture fibres. [27]

$$
\frac{\sigma}{V_{\mathrm{f}}}=T[1-P(T)]+\left\langle T_{\mathrm{b}}\right\rangle P(T)
$$

where $\left\langle T_{\mathrm{b}}\right\rangle$ denotes the stress carried by broken fibres; and $P(T)$ denotes the fibre failure probability.

$$
P(T)=1-\exp \left[-\left(\frac{T}{\sigma_{\mathrm{c}}}\right)^{m+1}\right]
$$

where $m$ denotes the fibre Weibull modulus, which describes the variation in the fibre strength; and $\sigma_{\mathrm{c}}$ denotes the fibre characteristic strength of a length $\delta_{\mathrm{c}}$ of the fibre. [27]

$$
\sigma_{\mathrm{c}}=\left(\frac{l_{0} \sigma_{0}^{m} \tau_{\mathrm{i}}}{r_{\mathrm{f}}}\right)^{\frac{1}{m+1}}, \delta_{\mathrm{c}}=\left(\frac{\sigma_{0} r_{\mathrm{f}} l_{0}^{1 / m}}{\tau_{\mathrm{i}}}\right)^{\frac{m}{m+1}}
$$

where $\sigma_{0}$ denotes the fibre strength of a length of $l_{0}$.

When a fibre breaks, the stress carried by the fibre drops to zero at the position of the break. Similar to the case of matrix cracking, the fibre/matrix interface debonds and the stress builds up in the fibre through the interface shear stress. During the process of loading, the stress in a broken fibre $T_{\mathrm{b}}$ as a function of the distance $x$ from the break can be written by the following equation:

$$
T_{\mathrm{b}}(x)=\frac{2 \tau_{\mathrm{i}}}{r_{\mathrm{f}}} x
$$

In order to calculate the average stress carried by broken fibres $\left\langle T_{\mathrm{b}}\right\rangle$, it is necessary to construct the probability distribution $F(x)$ of the distance $x$ of a fibre break from the reference matrix crack plane, provided that a break occurs within a distance $\pm l_{\mathrm{f}}$. For this conditional probability distribution, Phoenix and Raj [28] deduced the following equation based on Weibull statistics.

$$
F(x)=\frac{1}{P(T) l_{\mathrm{f}}}\left(\frac{T}{\sigma_{\mathrm{c}}}\right)^{m+1} \exp \left[-\left(\frac{x}{l_{\mathrm{f}}}\right)\left(\frac{T}{\sigma_{\mathrm{c}}}\right)^{m+1}\right], x \in\left[0, l_{\mathrm{f}}\right]
$$

where

$$
l_{\mathrm{f}}=\frac{r_{\mathrm{f}} T}{2 \tau_{\mathrm{i}}}
$$

The averaging stress carried by broken fibres $\left\langle T_{\mathrm{b}}\right\rangle$ during the process of loading using Equations 9 and 10 leads to the following equation:

$$
\left\langle T_{\mathrm{b}}\right\rangle=T\left[\left(\frac{\sigma_{\mathrm{c}}}{T}\right)^{m+1}-\frac{1-P(T)}{P(T)}\right]
$$

Substituting Equations 7 and 12 into Equation 6, it leads into the following equation:

$$
\frac{\sigma}{V_{\mathrm{f}}}=T\left(\frac{\sigma_{\mathrm{c}}}{T}\right)^{m+1}\left\{1-\exp \left[-\left(\frac{T}{\sigma_{\mathrm{c}}}\right)^{m+1}\right]\right\}
$$

Using Equation 13, the stress $T$ carried by the intact fibres at the matrix cracking plane can be determined. Substituting the intact fibre stress $T$ into Equation 7, the relationship between the fibre failure probability and the applied stress can be determined.

\section{Interface debonding}

When the matrix cracking propagates to the fibre/ matrix interface, it deflects along the interface. A fracture mechanics approach is adopted in the present analysis. The fibre/matrix interface debonding criterion is determined using the following equation: [23]

$$
\zeta_{\mathrm{d}}=-\frac{F}{4 \pi r_{\mathrm{f}}} \frac{\partial w_{\mathrm{f}}(0)}{\partial l_{\mathrm{d}}}-\frac{1}{2} \int_{0}^{l_{\mathrm{d}}} \tau_{\mathrm{i}} \frac{\partial v(x)}{\partial l_{\mathrm{d}}} d x
$$

where $\zeta_{\mathrm{d}}$ denotes the fibre/matrix interface debonded energy; $\left.F=\pi \mathrm{r}_{\mathrm{f}}^{2} \sigma / V_{\mathrm{f}}\right)$ denotes the fibre load at the matrix cracking plane; $w_{\mathrm{f}}(0)$ denotes the fibre axial displacement on the matrix cracking plane; and $v(x)$ denotes the relative displacement between the fibre and the matrix.

The axial displacements of the fibre and the matrix, i.e., $w_{\mathrm{f}}(x)$ and $w_{\mathrm{m}}(x)$, are determined by the following equations:

$$
\begin{aligned}
w_{\mathrm{f}}(x)= & \int_{x}^{l_{\mathrm{c}} / 2} \frac{\sigma_{\mathrm{f}}(x)}{E_{\mathrm{f}}} d x=\frac{T}{E_{\mathrm{f}}}\left(l_{\mathrm{d}}-x\right)-\frac{\tau_{\mathrm{i}}}{r_{\mathrm{f}} E_{\mathrm{f}}}\left(l_{\mathrm{d}}^{2}-x^{2}\right)+ \\
& +\frac{\sigma_{\mathrm{fo}}}{E_{\mathrm{f}}}\left(\frac{l_{\mathrm{c}}}{2}-l_{\mathrm{d}}\right)+\frac{r_{\mathrm{f}}}{\rho E_{\mathrm{f}}}\left(T-\sigma_{\mathrm{fo}}-2 \frac{l_{\mathrm{d}}}{r_{\mathrm{f}}} \tau_{\mathrm{i}}\right) \\
w_{\mathrm{m}}(x) & =\int_{x}^{l_{\mathrm{c}} / 2} \frac{\sigma_{\mathrm{m}}(x)}{E_{\mathrm{m}}} d x=\frac{V_{\mathrm{f}} \tau_{\mathrm{i}}}{r_{\mathrm{f}} V_{\mathrm{m}} E_{m}}\left(l_{\mathrm{d}}^{2}-x^{2}\right)+ \\
& +\frac{\sigma_{\mathrm{mo}}}{E_{\mathrm{m}}}\left(\frac{l_{\mathrm{c}}}{2}-l_{\mathrm{d}}\right)-\frac{r_{\mathrm{f}} V_{\mathrm{f}}}{\rho V_{\mathrm{m}} E_{\mathrm{m}}}\left[T-\sigma_{\mathrm{fo}}-2 \tau_{\mathrm{i}} \frac{l_{\mathrm{d}}}{r_{\mathrm{f}}}\right]
\end{aligned}
$$

The relative displacement between the fibre and the matrix, i.e., $\mathrm{v}(\mathrm{x})$, is determined by the following equation: 


$$
\begin{aligned}
v(x) & =\left|w_{\mathrm{f}}(x)-w_{\mathrm{m}}(x)\right| \\
& =\frac{T}{E_{\mathrm{f}}}\left(l_{\mathrm{d}}-x\right)-\frac{E_{\mathrm{c}} \tau_{\mathrm{i}}}{r_{\mathrm{f}} V_{\mathrm{m}} E_{\mathrm{m}} E_{\mathrm{f}}}\left(l_{\mathrm{d}}^{2}-x^{2}\right)+ \\
& +\frac{r_{\mathrm{f}} E_{\mathrm{c}}}{\rho V_{\mathrm{m}} E_{\mathrm{m}} E_{\mathrm{f}}}\left(T-\sigma_{\mathrm{fo}}-2 \frac{l_{\mathrm{d}}}{r_{\mathrm{f}}} \tau_{\mathrm{i}}\right)
\end{aligned}
$$

Substituting $w_{\mathrm{f}}(x=0)$ and $v(x)$ into Equation 14, leads to the following equation:

$$
\begin{aligned}
\frac{E_{\mathrm{c}} \tau_{\mathrm{i}}^{2}}{r_{\mathrm{f}} V_{\mathrm{m}} E_{\mathrm{m}} E_{\mathrm{f}}} l_{\mathrm{d}}^{2} & +\left(\frac{E_{\mathrm{c}} \tau_{\mathrm{i}}^{2}}{\rho V_{\mathrm{m}} E_{\mathrm{m}} E_{\mathrm{f}}}-\frac{\tau_{\mathrm{i}} T}{E_{\mathrm{f}}}\right) l_{\mathrm{d}}+ \\
& +\left(\frac{r_{\mathrm{f}} T^{2}}{4 E_{\mathrm{f}}}-\frac{r_{\mathrm{f}} T \sigma}{4 E_{\mathrm{c}}}-\frac{r_{\mathrm{f}} \tau_{\mathrm{i}} T}{2 \rho E_{\mathrm{f}}}-\zeta_{\mathrm{d}}\right)=0
\end{aligned}
$$

Solving Equation 18, the fibre/matrix interface debonded length $l_{\mathrm{d}}$ is determined by the following equation:

$$
\begin{aligned}
& l_{\mathrm{d}}=\frac{r_{\mathrm{f}}}{2}\left(\frac{V_{\mathrm{m}} E_{\mathrm{m}}}{E_{\mathrm{c}} \tau_{\mathrm{i}}} T-\frac{1}{\rho}\right)- \\
& -\sqrt{\left(\frac{r_{\mathrm{f}}}{2 \rho}\right)^{2}-\frac{r_{\mathrm{f}}^{2} V_{\mathrm{f}} V_{\mathrm{m}} E_{\mathrm{f}} E_{\mathrm{m}} T}{4 E_{\mathrm{c}}^{2} \tau_{\mathrm{i}}^{2}}\left(T-\frac{\sigma}{V_{\mathrm{f}}}\right)+\frac{r_{\mathrm{f}} V_{\mathrm{m}} E_{\mathrm{m}} E_{\mathrm{f}}}{E_{\mathrm{c}} \tau_{\mathrm{i}}^{2}} \zeta_{\mathrm{d}}}
\end{aligned}
$$

\section{Matrix multi-cracking}

Solti et al. [22] developed the critical matrix strain energy (CMSE) criterion to predict the matrix multicracking evolution in fibre-reinforced CMCs. The concept of a critical matrix strain energy presupposes the existence of an ultimate or critical strain energy. Beyond the critical value of the matrix strain energy, as more energy is entered into the composite with increasing applied stress, the matrix cannot support the extra load and continues to fail. The failure is assumed to consist of the formation of new cracks and the fibre/matrix interface debonding, to make the total energy within the matrix remain constant and equal to its critical value.

The matrix strain energy is determined using the following equation:

$$
U_{\mathrm{m}}=\frac{1}{2 E_{\mathrm{m}}} \int_{A_{\mathrm{m}}} \int_{0}^{l_{\mathrm{c}}} \sigma_{\mathrm{m}}^{2}(x) d x d A_{\mathrm{m}}
$$

where $A_{\mathrm{m}}$ is the cross-section area of the matrix in the unit cell. Substituting the matrix axial stresses in Equation 2 into Equation 20, the matrix strain energy considering the matrix multi-cracking and fibre/matrix interface partially debonding, is described using the following equation:

$$
U_{\mathrm{m}}=\frac{A_{\mathrm{m}}}{E_{\mathrm{m}}}\left\{\frac{4}{3}\left(\frac{V_{\mathrm{f}} \tau_{\mathrm{i}}}{V_{\mathrm{m}} r_{\mathrm{f}}} l_{\mathrm{d}}\right)^{2} l_{\mathrm{d}}+\sigma_{\mathrm{mo}}^{2}\left(\frac{l_{\mathrm{c}}}{2}-l_{\mathrm{d}}\right)-\right.
$$

$$
\begin{aligned}
& -2 \sigma_{\mathrm{mo}}\left[\frac{V_{\mathrm{f}}}{V_{\mathrm{m}}}\left(T-\sigma_{\mathrm{fo}}\right)-2 \frac{V_{\mathrm{f}} \tau_{\mathrm{i}}}{r_{\mathrm{f}} V_{\mathrm{m}}} l_{\mathrm{d}}\right]\left(-\frac{r_{f}}{\rho}\right)\left[\exp \left(-\rho \frac{l_{\mathrm{c}} / 2-l_{\mathrm{d}}}{r_{\mathrm{f}}}\right)-1\right]+ \\
& \left.+\left[\frac{V_{\mathrm{f}}}{V_{\mathrm{m}}}\left(T-\sigma_{\mathrm{fo}}\right)-2 \frac{V_{\mathrm{f}} \tau_{\mathrm{i}}}{r_{\mathrm{f}} V_{\mathrm{m}}} l_{\mathrm{d}}\right]^{2}\left(-\frac{r_{f}}{2 \rho}\right)\left[\exp \left(-2 \rho \frac{l_{\mathrm{c}} / 2-l_{\mathrm{d}}}{r_{\mathrm{f}}}\right)-1\right]\right\}
\end{aligned}
$$

When the fibre/matrix interface completely debonds, the matrix strain energy is described using the following equation:

$$
U_{\mathrm{m}}\left(\sigma, l_{\mathrm{c}}, l_{\mathrm{d}}=l_{\mathrm{c}} / 2\right)=\frac{A_{\mathrm{m}} l_{\mathrm{c}}^{3}}{6 E_{\mathrm{m}}}\left(\frac{\tau_{\mathrm{i}} V_{\mathrm{f}}}{r_{\mathrm{f}} V_{\mathrm{m}}}\right)^{2}
$$

By evaluating the matrix strain energy at a critical stress of $\sigma_{c r}$, the critical matrix strain energy of $U_{\text {crm }}$ can be obtained. The critical matrix strain energy is described using the following equation:

$$
U_{\mathrm{crm}}=\frac{1}{2} k A_{\mathrm{m}} l_{0} \frac{\sigma_{\mathrm{mocr}}^{2}}{E_{\mathrm{m}}}
$$

where $k(k \in[0,1])$ is the critical matrix strain energy parameter; and $l_{0}$ is the initial matrix crack spacing and $\sigma_{\text {mocr }}$ is determined using the following equation:

$$
\sigma_{\text {mocr }}=\frac{E_{\mathrm{m}}}{E_{\mathrm{c}}} \sigma_{\mathrm{cr}}+E_{\mathrm{m}}\left(\alpha_{\mathrm{c}}-\alpha_{\mathrm{m}}\right) \Delta \mathrm{T}
$$

where $\sigma_{\mathrm{cr}}$ is the critical stress corresponding to the composite's proportional limit stress, i.e., the stress at which the stress-strain curve starts to deviate from linearity due to damage accumulation of the matrix cracks [29]. The critical stress is defined to be the AvestonCooper-Kelly matrix cracking stress [13], which was determined using the energy balance criterion, involving the calculation of the energy balance relationship before and after the formation of a single dominant crack. The Aveston-Cooper-Kelly model can be used to describe the long-steady-state matrix cracking stress, corresponding to the proportional limit stress of the tensile stress-strain curve. The Aveston-Cooper-Kelly matrix cracking stress is determined using the following equation: [13]

$$
\sigma_{\mathrm{cr}}=\left(\frac{6 V_{\mathrm{f}}^{2} E_{\mathrm{f}} E_{\mathrm{c}}^{2} \tau_{\mathrm{i}} \zeta_{\mathrm{m}}}{r_{\mathrm{f}} V_{\mathrm{m}} E_{\mathrm{m}}^{2}}\right)^{\frac{1}{3}}-E_{\mathrm{c}}\left(\alpha_{\mathrm{c}}-\alpha_{\mathrm{m}}\right) \Delta \mathrm{T}
$$

where $\zeta_{\mathrm{m}}$ denotes the matrix fracture energy. However, as microcracks exist in the matrix when CMCs were cooled down from the high fabrication temperature to room temperature, due to a thermal expansion coefficient misfit between the fibre and the matrix, these microcracks are short-matrix-cracking, and the cracking stresses of these microcracks lie in the linear region of tensile stress-strain curve $[30,31]$. With an increasing of the applied stress, the matrix microcracks can propagate into long-matrix-cracking. The matrix cracking stress of the Aveston-Cooper-Kelly model was used to determine the critical matrix strain energy. 
The energy balance relationship to evaluate the matrix multi-cracking evolution is determined using the following equation:

$$
U_{\mathrm{m}}\left(\sigma>\sigma_{\mathrm{cr}}, l_{\mathrm{c}}, l_{\mathrm{d}}\right)=U_{\mathrm{crm}}\left(\sigma_{\mathrm{cr}}, l_{0}\right)
$$

The matrix multi-cracking evolution versus the applied stress can be solved by Equation 26 when the critical matrix cracking stress of $\sigma_{\mathrm{cr}}$ and the fibre/matrix interface debonded length of $l_{\mathrm{d}}$ are determined by Equations 19 and 25.

\section{DISCUSSION}

The ceramic composite system of $\mathrm{SiC} / \mathrm{CAS}$ is used for the case study and its material properties are given by [14]: $\mathrm{V}_{\mathrm{f}}=30 \%, E_{\mathrm{f}}=200 \mathrm{GPa}, E_{\mathrm{m}}=97 \mathrm{GPa}, r_{\mathrm{f}}=7.5 \mu \mathrm{m}$, $\zeta_{\mathrm{m}}=6 \mathrm{~J} \cdot \mathrm{m}^{-2}, \zeta_{\mathrm{d}}=0.8 \mathrm{~J} \cdot \mathrm{m}^{-2}, \tau_{\mathrm{i}}=20 \mathrm{MPa}, \alpha_{\mathrm{f}}=4 \times 10^{-5} /{ }^{\circ} \mathrm{C}$, $\alpha_{\mathrm{m}}=5 \times 10^{-5} /{ }^{\circ} \mathrm{C}, \Delta \mathrm{T}=-1000^{\circ} \mathrm{C}, m=4$, and $\sigma_{\mathrm{c}}=2.0 \mathrm{GPa}$.

\section{Effect of the fibre volume fraction}

The matrix cracking density, the fibre/matrix interface debonded length $\left(2 l_{\mathrm{d}} / l_{\mathrm{c}}\right)$ and the broken fibres fraction for the different fibre volume fractions (i.e., $V_{\mathrm{f}}=30 \%$ and $35 \%$ ) are shown in Figure 2.

When the fibre volume fraction is $\mathrm{V}_{\mathrm{f}}=30 \%$, the matrix cracking density increases from $0.15 / \mathrm{mm}$ at the first matrix cracking stress of $201 \mathrm{MPa}$ to $3.9 / \mathrm{mm}$ at the saturation matrix cracking stress of $310 \mathrm{MPa}$; the fibre/ matrix interface debonded length $\left(2 l_{\mathrm{d}} / l_{\mathrm{c}}\right)$ increases from $0.8 \%$ to $75.7 \%$; and the broken fibres fraction increases from $0.4 \%$ to $9.4 \%$.

When the fibre volume fraction is $V_{\mathrm{f}}=35 \%$, the matrix cracking density increases from $0.19 / \mathrm{mm}$ at the first matrix cracking stress of $235 \mathrm{MPa}$ to $4.5 / \mathrm{mm}$ at the saturation matrix cracking stress of $360 \mathrm{MPa}$; the fibre/ matrix interface debonded length $\left(2 l_{\mathrm{d}} / l_{\mathrm{c}}\right)$ increases from $0.8 \%$ to $52.2 \%$; and the broken fibres fraction increases from $0.4 \%$ to $3.9 \%$.
With an increasing fibre volume fraction, the first matrix cracking stress, the matrix saturation cracking stress and the cracking density increase, and the matrix cracking evolves with a higher applied stress; and the fibre/matrix interface debonded length and the broken fibres fraction decrease.

\section{Effect of the fibre/matrix interface shear stress}

The matrix cracking density, the fibre/matrix interface debonded length $\left(2 l_{\mathrm{d}} / l_{\mathrm{c}}\right)$ and the broken fibres fraction for the different fibre/matrix interface shear stress (i.e., $\tau_{\mathrm{i}}=10$ and $15 \mathrm{MPa}$ ) are shown in Figure 3.

When the fibre/matrix interface shear stress is $\tau_{\mathrm{i}}=10 \mathrm{MPa}$, the matrix cracking density increases from $0.2 / \mathrm{mm}$ at the first matrix cracking stress of $147 \mathrm{MPa}$ to $3.3 / \mathrm{mm}$ at the saturation matrix cracking stress of $217 \mathrm{MPa}$; the fibre/matrix interface debonded length $\left(2 l_{\mathrm{d}} / l_{\mathrm{c}}\right)$ increases from $0.7 \%$ to $100 \%$; and the broken fibres fraction increases from $0.1 \%$ to $9.4 \%$.

When the fibre/matrix interface shear stress is $\tau_{\mathrm{i}}=15 \mathrm{MPa}$, the matrix cracking density increases from $0.16 / \mathrm{mm}$ at the first matrix cracking stress of $177 \mathrm{MPa}$ to $3.6 / \mathrm{mm}$ at the saturation matrix cracking stress of $274 \mathrm{MPa}$; the fibre/matrix interface debonded length $\left(2 l_{\mathrm{d}} / l_{\mathrm{c}}\right)$ increases from $0.8 \%$ to $92.6 \%$; and the broken fibres fraction increases from $0.2 \%$ to $9.4 \%$.

With an increasing fibre/matrix interface shear stress, the first matrix cracking stress, the matrix saturation cracking stress and the cracking density increase, the matrix cracking evolves with a higher applied stress; and the fibre/matrix interface debonded length decreases.

Effect of the fibre/matrix interface debonded energy

The matrix cracking density, the fibre/matrix interface debonded length $\left(2 l_{\mathrm{d}} / l_{\mathrm{c}}\right)$ and the broken fibres

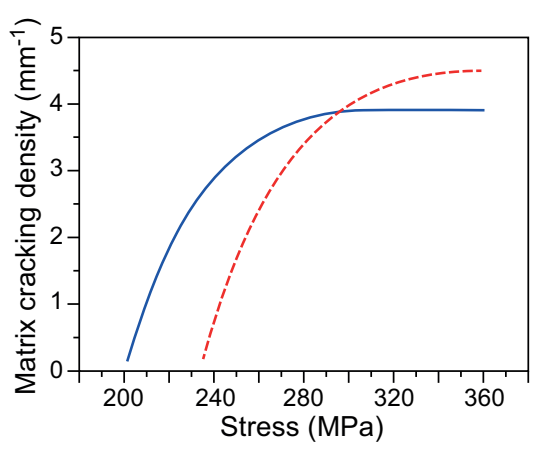

a)

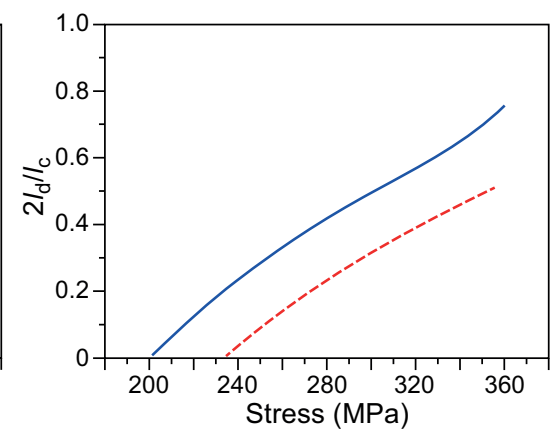

b)

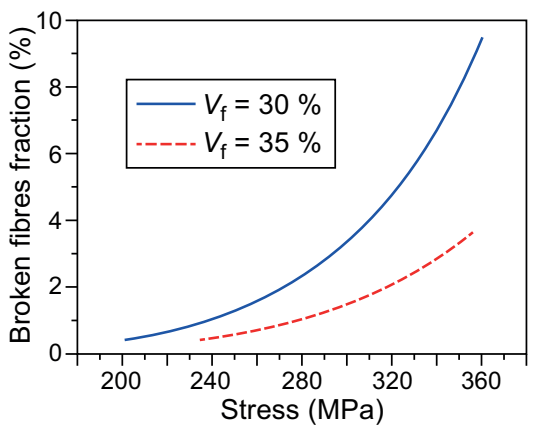

c)

Figure 2. The effect of the fibre volume fraction on: a) the matrix cracking density versus the applied stress curves; b) the fibre/ matrix interface debonding length $\left(2 l_{\mathrm{d}} / l_{\mathrm{c}}\right)$ versus the applied stress curves; and $\left.\mathrm{c}\right)$ the broken fibres fraction versus the applied cycles curves. 
fraction for the different fibre/matrix interface debonded energy (i.e., $\zeta_{\mathrm{d}}=0.5$ and $1.0 \mathrm{~J} \cdot \mathrm{m}^{-2}$ ) are shown in Figure 4.

When the fibre/matrix interface debonded energy is $\zeta_{\mathrm{d}}=0.5 \mathrm{~J} \cdot \mathrm{m}^{-2}$, the matrix cracking density increases from $0.13 / \mathrm{mm}$ at the first matrix cracking stress of $201 \mathrm{MPa}$ to $3.6 / \mathrm{mm}$ at the saturation matrix cracking stress of $320 \mathrm{MPa}$; the fibre/matrix interface debonded length $\left(2 l_{\mathrm{d}} / l_{\mathrm{c}}\right)$ increases from $0.9 \%$ to $79.7 \%$; and the broken fibres fraction increases from $0.4 \%$ to $9.4 \%$.

When the fibre/matrix interface debonded energy is $\zeta_{\mathrm{d}}=1.0 \mathrm{~J} \cdot \mathrm{m}^{-2}$, the matrix cracking density increases from $0.18 / \mathrm{mm}$ at the first matrix cracking stress of $201 \mathrm{MPa}$ to $4.1 / \mathrm{mm}$ at the saturation matrix cracking stress of $304 \mathrm{MPa}$; the fibre/matrix interface debonded length $\left(2 l_{\mathrm{d}} / l_{\mathrm{c}}\right)$ increases from $0.8 \%$ to $74.7 \%$; and the broken fibres fraction increases from $0.4 \%$ to $9.4 \%$.

With increasing fibre/matrix interface debonded energy, the first matrix cracking stress remains the same, the matrix cracking saturation stress decreases, and the saturation matrix cracking density increase, and the rate of matrix cracking development increases due to the decrease of the fibre/matrix interface debonding ratio.
Effect of the fibre Weibull modulus

The matrix cracking density, the fibre/matrix interface debonded length $\left(2 l_{\mathrm{d}} / l_{\mathrm{c}}\right)$ and the broken fibres fraction for the different fibre Weibull modulus (i.e., $m=3$ and 5) are shown in Figure 5.

When the fibre Weibull modulus is $m=3$, the matrix cracking density increases from $0.18 / \mathrm{mm}$ at the first matrix cracking stress of $201 \mathrm{MPa}$ to $3.9 / \mathrm{mm}$ at the saturation matrix cracking stress of $298 \mathrm{MPa}$; the fibre/ matrix interface debonded length $\left(2 l_{\mathrm{d}} / l_{\mathrm{c}}\right)$ increases from $0.8 \%$ to $85.7 \%$; and the broken fibres fraction increases from $1.2 \%$ to $17 \%$.

When the fibre Weibull modulus is $m=5$, the matrix cracking density increases from $0.18 / \mathrm{mm}$ at the first matrix cracking stress of $201 \mathrm{MPa}$ to $4.2 / \mathrm{mm}$ at the saturation matrix cracking stress of $310 \mathrm{MPa}$; the fibre/ matrix interface debonded length $\left(2 l_{\mathrm{d}} / l_{\mathrm{c}}\right)$ increases from $0.8 \%$ to $70.4 \%$; and the broken fibres fraction increases from $0.1 \%$ to $5.3 \%$.

With an increasing fibre Weibull modulus, the first matrix cracking stress remains the same, the saturation matrix cracking stress and the cracking density increase; and the fibre/matrix interface debonded length and the broken fibres fraction decrease.

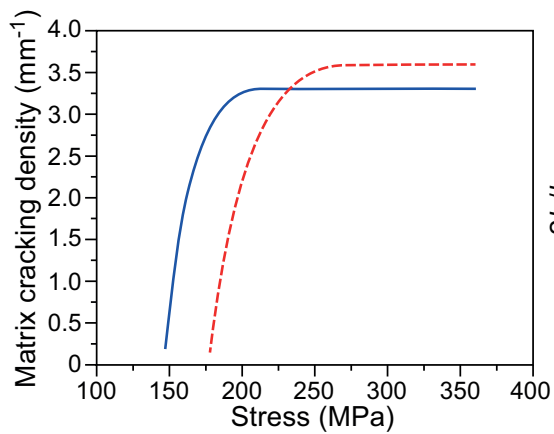

a)

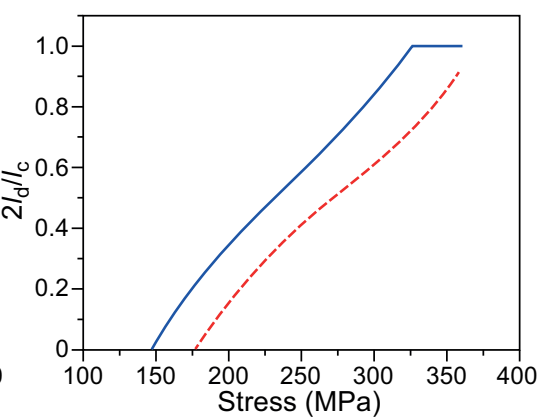

b)

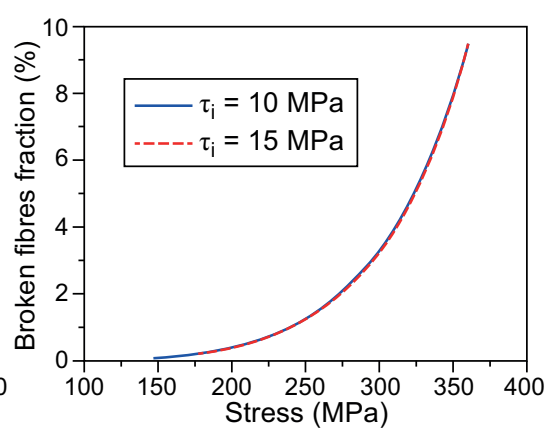

c)

Figure 3. The effect of the fibre/matrix interface shear stress on: a) the matrix cracking density versus the applied stress curves; b) the fibre/matrix interface debonding length $\left(2 l_{\mathrm{d}} / l_{\mathrm{c}}\right)$ versus the applied stress curves; and $\left.\mathrm{c}\right)$ the broken fibres fraction versus the applied cycles curves.

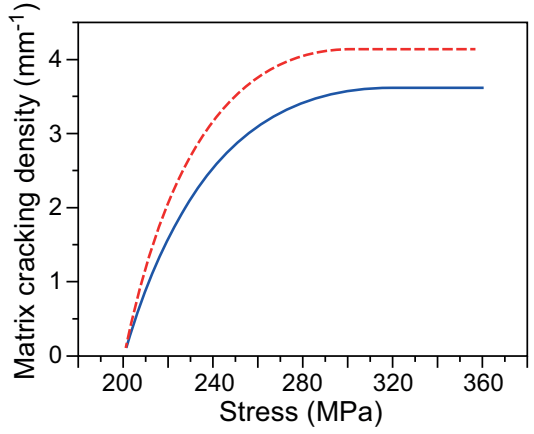

a)

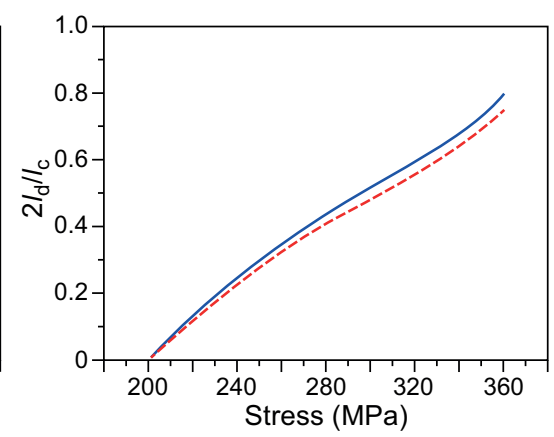

b)

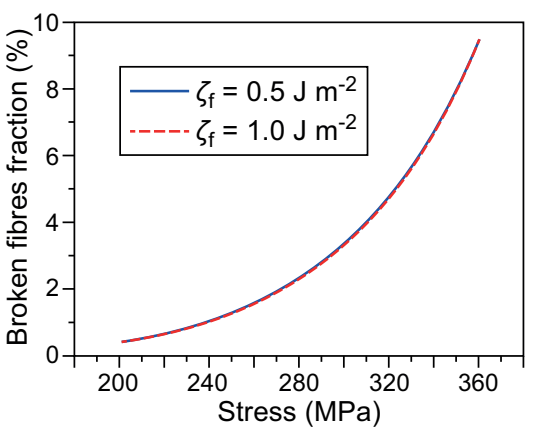

c)

Figure 4. The effect of the fibre/matrix interface debonded energy on: a) the matrix cracking density versus the applied stress curves; b) the fibre/matrix interface debonding length $\left(2 l_{\mathrm{d}} / l_{\mathrm{c}}\right)$ versus the applied stress curves; and c) the broken fibres fraction versus the applied cycles curves. 
Effect of the fibre strength

The matrix cracking density, the fibre/matrix interface debonded length $\left(2 l_{\mathrm{d}} / l_{\mathrm{c}}\right)$ and the broken fibres fraction for different fibre strengths (i.e., $\sigma_{\mathrm{c}}=2.0$ and $2.5 \mathrm{GPa}$ ) are shown in Figure 6.

When the fibre strength is $\sigma_{\mathrm{c}}=2.0 \mathrm{GPa}$, the matrix cracking density increases from $0.18 / \mathrm{mm}$ at the first matrix cracking stress of $201 \mathrm{MPa}$ to $4.1 / \mathrm{mm}$ at the saturation matrix cracking stress of $304 \mathrm{MPa}$; the fibre/ matrix interface debonded length $\left(2 l_{\mathrm{d}} / l_{\mathrm{c}}\right)$ increases from $0.8 \%$ to $74.7 \%$; and the broken fibres fraction increases from $0.4 \%$ to $9.4 \%$.

When the fibre strength is $\sigma_{\mathrm{c}}=2.5 \mathrm{GPa}$, the matrix cracking density increases from $0.18 / \mathrm{mm}$ at the first matrix cracking stress of $201 \mathrm{MPa}$ to $4.3 / \mathrm{mm}$ at the saturation matrix cracking stress of $317 \mathrm{MPa}$; the fibre/ matrix interface debonded length $\left(2 l_{\mathrm{d}} / l_{\mathrm{c}}\right)$ increases from $0.8 \%$ to $67.6 \%$; and the broken fibres fraction increases from $0.1 \%$ to $2.7 \%$.

With an increasing fibre strength, the first matrix cracking stress remains the same, the saturation matrix cracking stress and the cracking density increase; and the fibre/matrix interface debonded length and the broken fibres fraction decrease.

\section{DISCUSSION}

The experimental and theoretical matrix cracking density, the fibre/matrix interface debonded length $\left(2 l_{\mathrm{d}} / l_{\mathrm{c}}\right)$ and the broken fibres fraction versus the applied stress for the different CMCs, i.e., unidirectional $\mathrm{SiC} / \mathrm{CAS}$ [12], $\mathrm{SiC} / \mathrm{CAS}-\mathrm{II}$ [14], SiC/SiC [14], SiC/Borosilicate [16] and $\mathrm{mini}-\mathrm{SiC} / \mathrm{SiC}$ [32] composites are predicted using the present analysis, as shown in Figures $7 \sim 11$. The material properties of the CMCs are listed in Table 1.

For the SiC/CAS composite, the matrix cracking evolution starts from the applied stress of $160 \mathrm{MPa}$ and approaches saturation at the applied stress of $278 \mathrm{MPa}$; the matrix cracking density increases from $0.3 / \mathrm{mm}$ to the saturation value of $7.1 / \mathrm{mm}$; the fibre/matrix interface debonded length increases from $0.7 \%$ to $82.6 \%$; and the broken fibres fraction increases from $0.01 \%$ to $2.3 \%$, as shown in Figure 7.

For the SiC/CAS-II composite, the matrix cracking evolution starts from the applied stress of $260 \mathrm{MPa}$ and approaches saturation at the applied stress of $354 \mathrm{MPa}$; the matrix cracking density increases from $0.7 / \mathrm{mm}$ to the saturation value of $9.3 / \mathrm{mm}$; the fibre/matrix interface debonded length increases from $0.3 \%$ to $40.5 \%$; and the

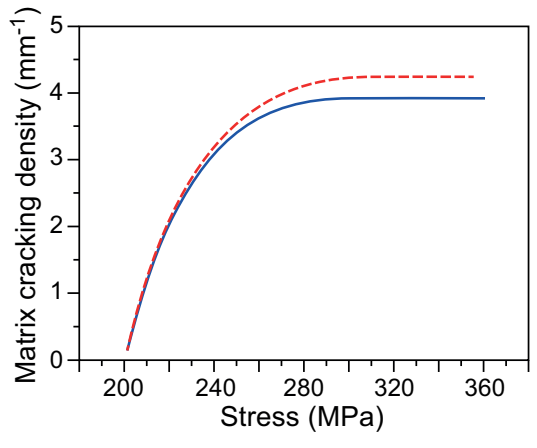

a)

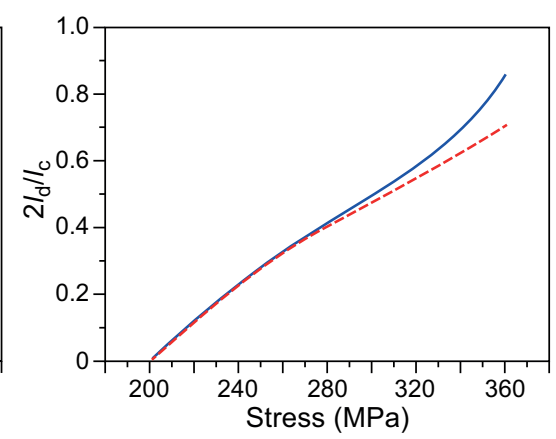

b)

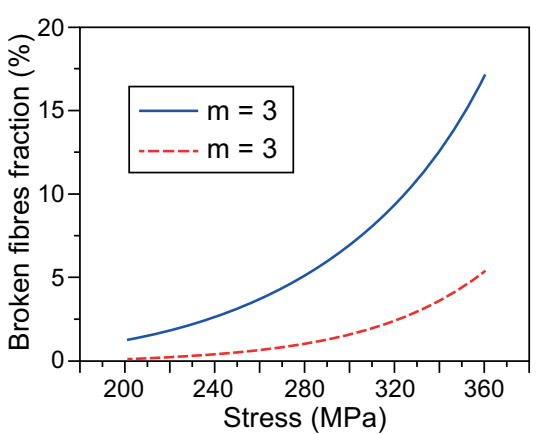

c)

Figure 5. The effect of the fibre Weibull modulus on: a) the matrix cracking density versus the applied stress curves; b) the fibre/ matrix interface debonding length $\left(2 l_{\mathrm{d}} / l_{\mathrm{c}}\right)$ versus the applied stress curves; and $\left.\mathrm{c}\right)$ the broken fibres fraction versus the applied cycles curves.

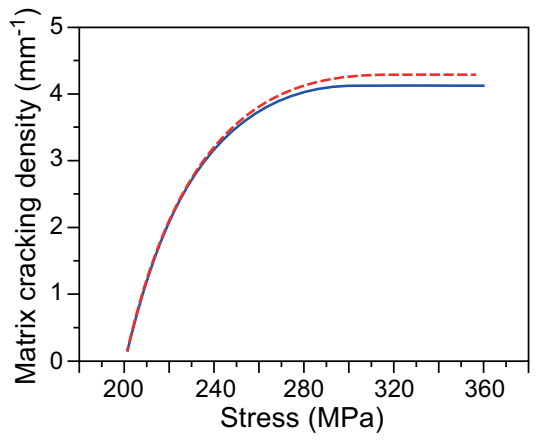

a)

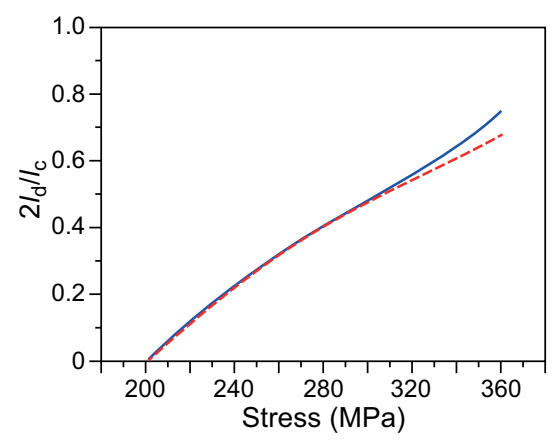

b)

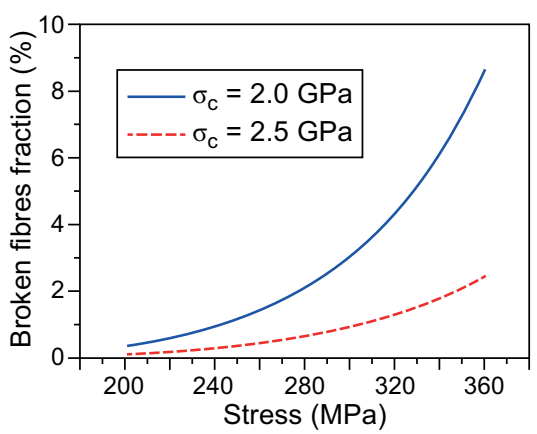

c)

Figure 6. The effect of the fibre strength on: a) the matrix cracking density versus the applied stress curves; $b$ ) the fibre/matrix interface debonding length $\left(2 l_{\mathrm{d}} / l_{\mathrm{c}}\right)$ versus the applied stress curves; and $\left.\mathrm{c}\right)$ the broken fibres fraction versus the applied cycles curves. 
broken fibres fraction increases from $0.11 \%$ to $1.2 \%$, as shown in Figure 8.

For the $\mathrm{SiC} / \mathrm{SiC}$ composite, the matrix cracking evolution starts from the applied stress of $240 \mathrm{MPa}$ and approaches saturation at the applied stress of $290 \mathrm{MPa}$; the matrix cracking density increases from $1.4 / \mathrm{mm}$ to the saturation value of $15.8 / \mathrm{mm}$; the fibre/matrix interface debonded length increases from 0 to $27.8 \%$; and the broken fibres fraction increases from $0.07 \%$ to $0.41 \%$, as shown in Figure 9.
For the $\mathrm{SiC} /$ Borosilicate composite, the matrix cracking evolution starts from the applied stress of $220 \mathrm{MPa}$ and approaches saturation at the applied stress of $340 \mathrm{MPa}$; the matrix cracking density increases from $0.2 / \mathrm{mm}$ to the saturation value of $6.4 / \mathrm{mm}$; the fibre/ matrix interface debonded length increases from $0.8 \%$ to $100 \%$; and the broken fibres fraction increases from $0.2 \%$ to $14 \%$, as shown in Figure 10 .

For the mini-SiC/SiC composite, the matrix cracking evolution starts from the applied stress of $135 \mathrm{MPa}$

Table 1. The material properties of the $\mathrm{SiC} / \mathrm{CAS}, \mathrm{SiC} / \mathrm{CAS}-\mathrm{II}, \mathrm{SiC} / \mathrm{SiC}, \mathrm{SiC} /$ Borosilicate and the mini-SiC/SiC composites.

\begin{tabular}{|c|c|c|c|c|c|}
\hline Items & $\mathrm{SiC} / \mathrm{CAS}[12]$ & $\mathrm{SiC} / \mathrm{CAS}-\mathrm{II}[14]$ & $\mathrm{SiC} / \mathrm{SiC}[14]$ & SiC/Borosilicate [16] & $\mathrm{mini}-\mathrm{SiC} / \mathrm{SiC}$ [32] \\
\hline$E_{\mathrm{f}}(\mathrm{GPa})$ & 190 & 200 & 200 & 230 & 160 \\
\hline$E_{\mathrm{m}}(\mathrm{GPa})$ & 90 & 97 & 300 & 60 & 190 \\
\hline$V_{\mathrm{f}}$ & 0.34 & 0.4 & 0.4 & 0.31 & 0.25 \\
\hline$r_{\mathrm{f}}(\mu \mathrm{m})$ & 7.5 & 7.5 & 7.5 & 8 & 6.5 \\
\hline$\alpha_{\mathrm{f}}\left(10^{-6} /{ }^{\circ} \mathrm{C}\right)$ & 3.3 & 4 & 4 & 3.1 & 3.1 \\
\hline$\alpha_{\mathrm{m}}\left(10-6 /{ }^{\circ} \mathrm{C}\right)$ & 4.6 & 5 & 5 & 3.25 & 4.6 \\
\hline$\tau_{\mathrm{i}}(\mathrm{MPa})$ & 10 & 25 & 50 & 7.6 & 15 \\
\hline$\zeta_{\mathrm{d}}\left(\mathrm{J} \cdot \mathrm{m}^{-2}\right)$ & 0.4 & 1.8 & 2.8 & 0.2 & 0.4 \\
\hline$m$ & 5 & 5 & 5 & 5 & 5 \\
\hline$\sigma_{\mathrm{c}}(\mathrm{GPa})$ & 2 & 2 & 2 & 2 & 2 \\
\hline
\end{tabular}

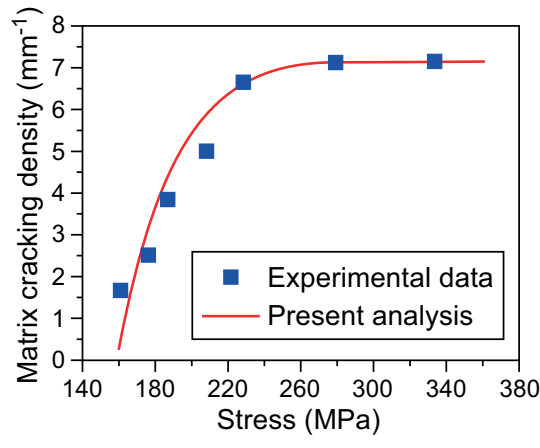

a)

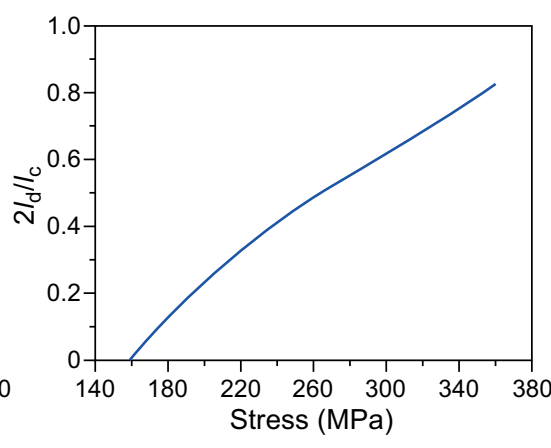

b)

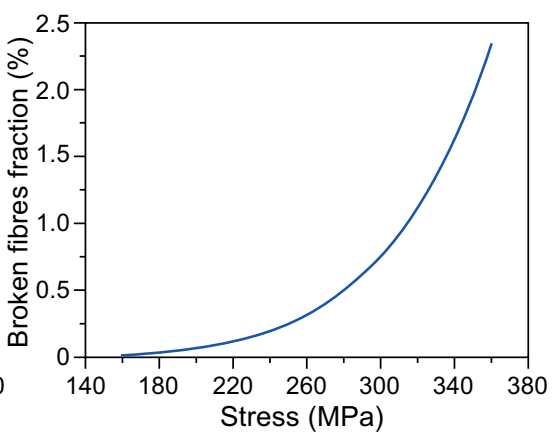

c)

Figure 7. a) the experimental and theoretical matrix cracking density versus the applied stress curves; b) the fibre/matrix interface debonded length $\left(2 l_{\mathrm{d}} / l_{\mathrm{c}}\right)$ versus the applied stress curves; and $\left.\mathrm{c}\right)$ the broken fibres fraction versus the applied stress curve of the unidirectional $\mathrm{SiC} / \mathrm{CAS}$ composite.

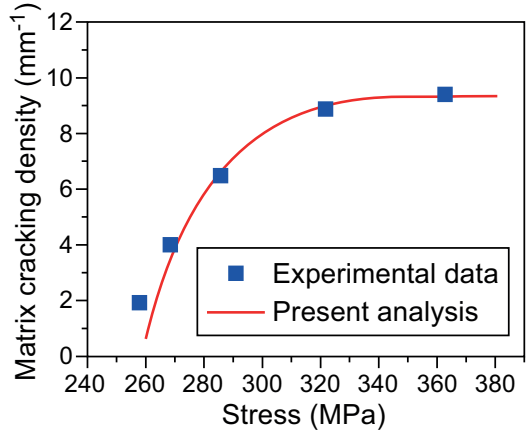

a)

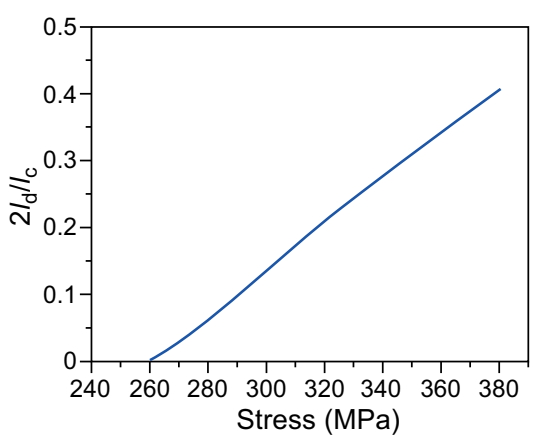

b)

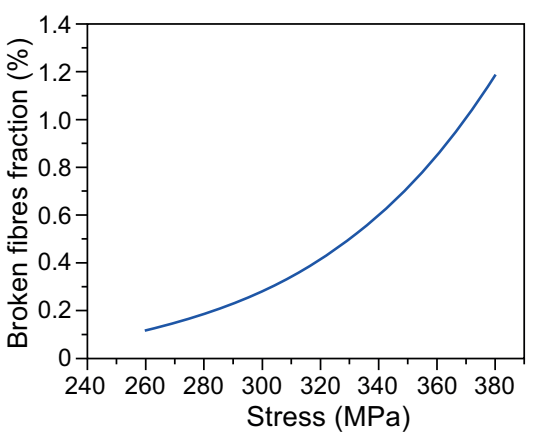

c)

Figure 8. a) the experimental and theoretical matrix cracking density versus the applied stress curves; b) the fibre/matrix interface debonded length $\left(2 l_{\mathrm{d}} / l_{\mathrm{c}}\right)$ versus the applied stress curves; and $\mathrm{c}$ ) the broken fibres fraction versus the applied stress curve of the unidirectional SiC/CAS-II composite. 
and approaches saturation at the applied stress of $240 \mathrm{MPa}$; the matrix cracking density increases from $0.1 / \mathrm{mm}$ to the saturation value of $2.4 / \mathrm{mm}$; the fibre/ matrix interface debonded length increases from $1 \%$ to $89 \%$; and the broken fibres fraction increases from $0.03 \%$ to $3.35 \%$, as shown in Figure 11 .

\section{CONCLUSIONS}

In this paper, the effect of fibre fracture on the matrix multi-cracking development of the CMCs has been investigated. The shear-lag model combined with the fibre fracture model and the fibre/matrix interface debonding criterion has been adopted to analyse the fibre and matrix axial stress distribution inside the damaged

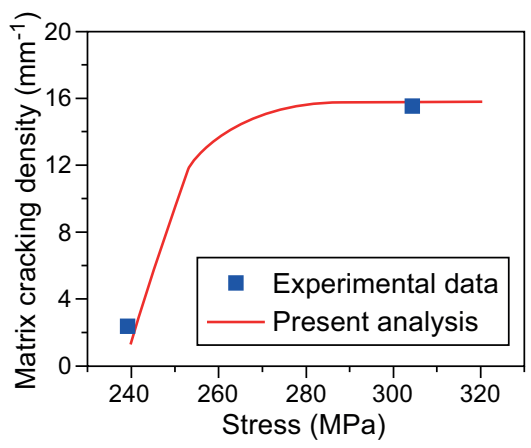

a)

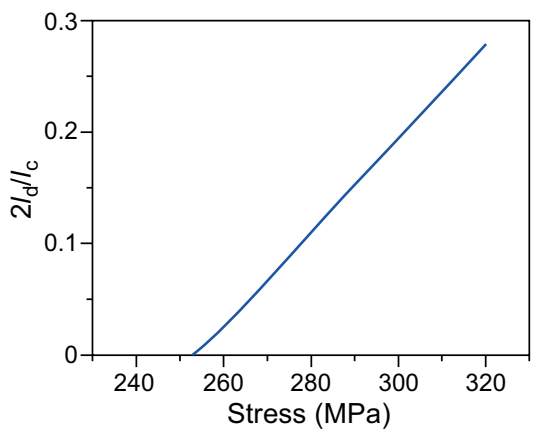

b)

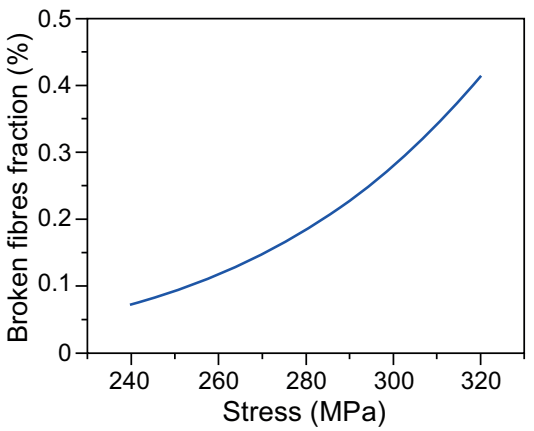

c)

Figure 9. a) the experimental and theoretical matrix cracking density versus the applied stress curves; b) the fibre/matrix interface debonded length $\left(2 l_{\mathrm{d}} / l_{\mathrm{c}}\right)$ versus the applied stress curves; and c) the broken fibres fraction versus the applied stress curve of the unidirectional $\mathrm{SiC} / \mathrm{SiC}$ composite.

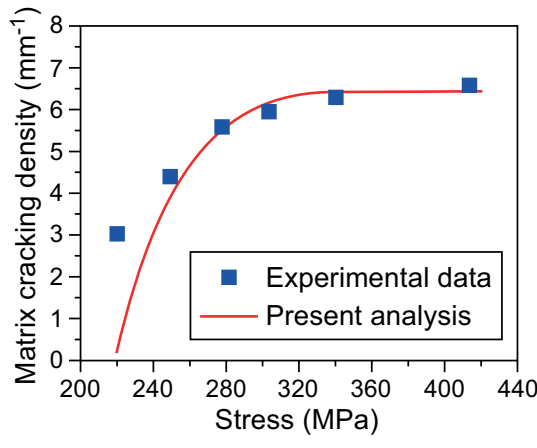

a)

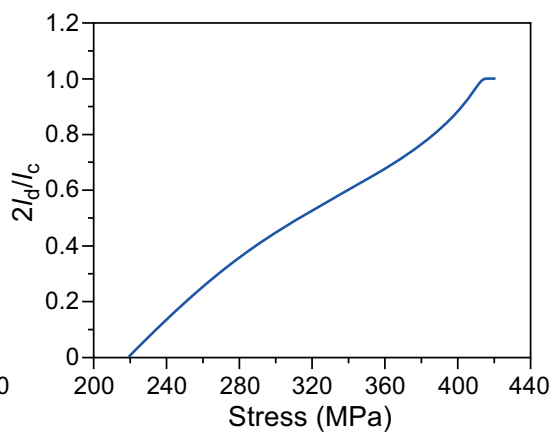

b)

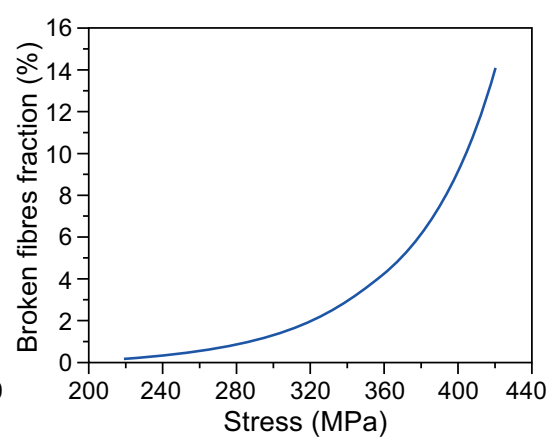

c)

Figure 10. a) the experimental and theoretical matrix cracking density versus the applied stress curves; b) the fibre/matrix interface debonded length $\left(2 l_{\mathrm{d}} / l_{\mathrm{c}}\right)$ versus the applied stress curves; and $\left.\mathrm{c}\right)$ the broken fibres fraction versus the applied stress curve of the unidirectional $\mathrm{SiC} /$ Borosilicate composite.

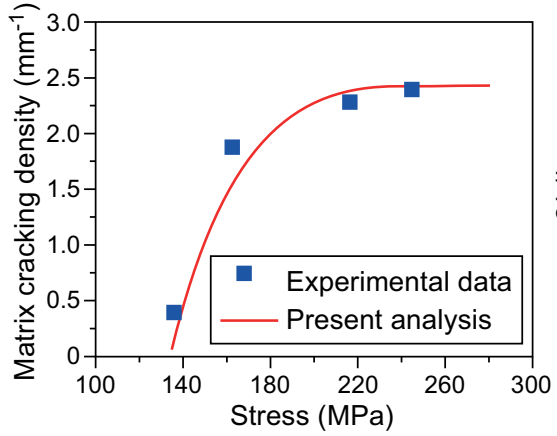

a)

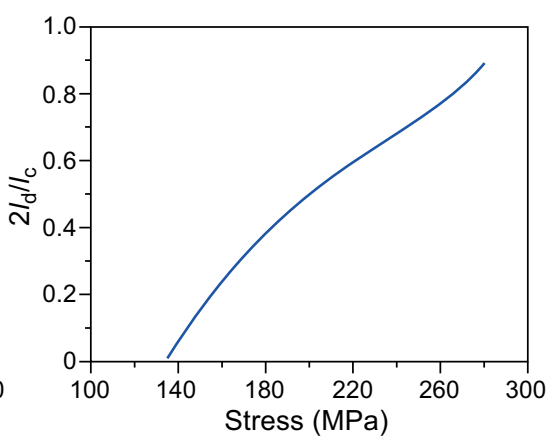

b)

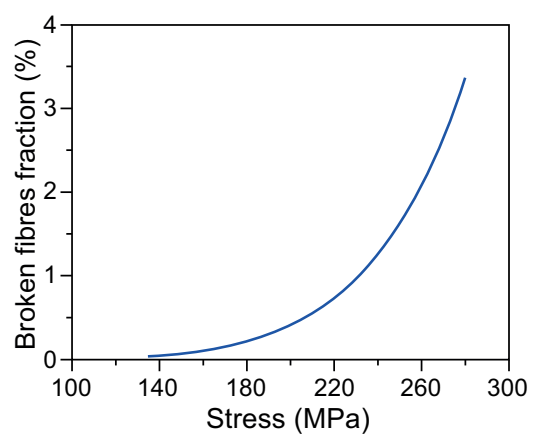

c)

Figure 11. a) the experimental and theoretical matrix cracking density versus the applied stress curves; b) the fibre/matrix interface debonded length $\left(2 l_{\mathrm{d}} / l_{\mathrm{c}}\right)$ versus the applied stress curves; and $\mathrm{c}$ ) the broken fibres fraction versus the applied stress curve of the mini-SiC/SiC composite. 
composite. The effects of the fibre volume fraction, the fibre/matrix interface shear stress, the fibre/matrix interface debonded energy, the fibre Weibull modulus and the fibre strength on the stress-dependent matrix multi-cracking development have been discussed. The experimental matrix multi-cracking development of the unidirectional SiC/CAS, SiC/CAS-II, SiC/SiC, SiC/ Borosilicate and the mini-SiC/SiC composites have been predicted.

- With an increasing fibre volume fraction, the first matrix cracking stress, the matrix saturation cracking stress and the cracking density increase, and the matrix cracking evolves with a higher applied stress; and the fibre/matrix interface debonded length and the broken fibres fraction decrease.

- With an increasing fibre/matrix interface shear stress, the first matrix cracking stress, the matrix cracking saturation stress and the saturation matrix cracking density increase, the matrix cracking evolves with a higher applied stress; and the fibre/matrix interface debonded length decreases.

- With an increasing fibre/matrix interface debonded energy, the first matrix cracking stress remains the same, the matrix saturation cracking stress decreases, and the saturation matrix cracking density increase, and the rate of matrix cracking development increases due to a decrease in the fibre/matrix interface debonding ratio.

- With an increasing fibre Weibull modulus and fibre strength, the first matrix cracking stress remains the same, the saturation matrix cracking stress and the cracking density increase; and the fibre/matrix interface debonded length and the broken fibres fraction decrease.

\section{Acknowledgements}

The work reported here is supported by the Fundamental Research Funds for the Central Universities (Grant No. NS2016070).

\section{REFERENCES}

1. Christin F. (2002): Design, fabrication, and application of thermostructural composites (TSC) like $\mathrm{C} / \mathrm{C}, \mathrm{C} / \mathrm{SiC}$, and $\mathrm{SiC} / \mathrm{SiC}$ composites. Advanced Engineering Materials, 4(12), 903-912. doi: 10.1002/adem.200290001

2. Naslain R. (2004): Design, preparation and properties of non-oxide CMCs for application in engines and nuclear reactors: an overview. Composites Science and Technology, 64(2), 155-170. doi: 10.1016/S0266-3538(03)00230-6

3. Schmid, S., Beyer S., Knabe H., Immich H., Meistring R., Gessler A. (2004): Advanced ceramic matrix composite materials for current and future propulsion technology applications. Acta Astronautica, 55(3-9), 409-420. doi: 10.1016/j.actaastro.2004.05.052
4. Cox B. N., Marshall D. B. (1996): Crack Initiation in Fiber-Reinforced Brittle Laminates. Journal of the American Ceramic Society, 79(5), 1181-1188. doi: 10.1111/j.11512916.1996.tb08570.x

5. Sevener K. M., Tracy J. M., Chen Z., Kiser J. D., Daly S. (2017): Crack opening behavior in ceramic matrix composites. Journal of the American Ceramic Society, 100(10), 4734-4747. doi: 10.1111/jace.14976

6. Filipuzzi L., Camus G., Naslain R., Thebault J. (1994): Oxidation mechanisms and kinetics of $1 \mathrm{D}-\mathrm{SiC} / \mathrm{c} / \mathrm{SiC}$ composite materials: I, an experimental approach. Journal of the American Ceramic Society, 77(2), 459-466. doi: 10.1111/ j.1151-2916.1994.tb07015.x

7. Lamouroux F., Naslain R., Jouin J. M. (1994): Kinetics and mechanisms of oxidation of $2 \mathrm{D}$ woven $\mathrm{C} / \mathrm{SiC}$ composites: II, theoretical approach. Journal of the American Ceramic Society, 77(8), 2058-2068. doi: 10.1111/j.1151-2916.1994. tb07097.x

8. Verrilli M. J., Opila E. J., Calomino A., Kiser J. D. (2004): Effect of Environment on the Stress-Rupture Behavior of a Carbon-Fiber-Reinforced Silicon Carbide Ceramic Matrix Composite. Journal of the American Ceramic Society, 87(8), 1536-1542. doi: 10.1111/j.1551-2916.2004.01536.x

9. Halbig M. C., McGuffin-Cawley J. D., Eckel A. J., Brewer D. N. (2008): Oxidation kinetics and stress effects for the oxidation of continuous carbon fibers within a microcracked $\mathrm{C} / \mathrm{SiC}$ ceramic matrix composite. Journal of the American ceramic society, 91(2), 519-526. doi: 10.1111/j. 1551-2916.2007.02170.x

10. Kuo W. S., Chou T. W. (1995): Multiple Cracking of Unidirectional and Cross-PlyCeramic Matrix Composites. Journal of the American Ceramic Society, 78(3), 745-755. doi: 10.1111/j.1151-2916.1995.tb08242.x

11. Parthasarathy T. A., Cox B., Sudre O., Przybyla C., Cinibulk M. K. (2018): Modeling environmentally induced property degradation of $\mathrm{SiC} / \mathrm{BN} / \mathrm{SiC}$ ceramic matrix composites. Journal of the American Ceramic Society, 101(3), 973-997. doi: 10.1111/jace.15325

12. Pryce A. W., Smith P. A. (1992): Behaviour of unidirectional and crossply ceramic matrix composites under quasistatic tensile loading. Journal of materials science, 27(10), 2695-2704. doi: 10.1007/BF00540692

13. Aveston J., Cooper G.A., Kelly A. (1971). Properties of Fiber Composites, in: Conference Proceedings of National Physical Laboratory. IPC Science and Technology Press, pp.15-26.

14. Beyerle D. S., Spearing S. M., Zok F. W., Evans A. G. (1992): Damage and failure in unidirectional ceramicmatrix composites. Journal of the American Ceramic Society, 75(10), 2719-2725. doi: 10.1111/j.1151-2916.1992. tb05495.x

15. Holmes J. W., Cho C. (1992): Experimental Observations of Frictional Heating in Fiber-Reinforced Ceramics. Journal of the American Ceramic Society, 75(4), 929-938. doi: 10.1111/j.1151-2916.1992.tb04162.x

16. Okabe T., Komotori J., Shimizu M., Takeda N. (1999): Mechanical behavior of $\mathrm{SiC}$ fiber reinforced brittle-matrix composites. Journal of materials science, 34(14), 3405-3412. doi: 10.1023/A:1004637300310

17. Smith C. E., Morscher G. N., Xia Z. H. (2008): Monitoring damage accumulation in ceramic matrix composites using electrical resistivity. Scripta Materialia, 59(4), 463-466. doi: 10.1016/j.scriptamat.2008.04.033 
18. Simon C., Rebillat F., Herb V., Camus G. (2017): Monitoring damage evolution of $\mathrm{SiCf} /[\mathrm{SiBC}] m$ composites using electrical resistivity: Crack density-based electromechanical modeling. Acta Materialia, 124, 579-587. doi: 10.1016/j.actamat.2016.11.036

19. Gowayed Y., Ojard G., Santhosh U., Jefferson G. (2015): Modeling of crack density in ceramic matrix composites. Journal of Composite Materials, 49(18), 2285-2294. doi: $10.1177 / 0021998314545188$

20. Ogasawara T., Ishikawa T., Ito H., Watanabe N., Davies I. J. (2001): Multiple Cracking and Tensile Behavior for an Orthogonal 3-D Woven $\mathrm{Si}-\mathrm{Ti}-\mathrm{C}-\mathrm{O}$ Fiber/Si-Ti-C-O Matrix Composite. Journal of the American Ceramic Society, 84(7), 1565-1574. doi: 10.1111/j.1151-2916.2001. tb00878.x

21. Morscher G. N., Yun H. M., DiCarlo J. A. (2005): Matrix Cracking in 3D Orthogonal Melt-Infiltrated $\mathrm{SiC} / \mathrm{SiC}$ Composites with Various Z-Fiber Types. Journal of the American Ceramic Society, 88(1), 146-153. doi: 10.1111/j. 1551-2916.2004.00029.x

22. Solti J. P., Mall S., Robertson D. D. (1995): Modeling damage in unidirectional ceramic-matrix composites. Composites science and technology, 54(1), 55-66. doi: 10.1016/ 0266-3538(95)00041-0

23. Gao Y. C., Mai Y. W., Cotterell B. (1988): Fracture of fiberreinforced materials. Zeitschrift für angewandte Mathematik und Physik ZAMP, 39(4), 550-572. doi: 10.1007/ BF00948962

24. Stang H., Shah S. P. (1986): Failure of fibre-reinforced composites by pull-out fracture. Journal of materials science, 21(3), 953-957. doi: 10.1007/BF01117378
25. Rajan V. P., Zok F. W. (2014): Matrix cracking of fiberreinforced ceramic composites in shear. Journal of the Mechanics and Physics of Solids, 73, 3-21. doi: 10.1016/j. jmps.2014.08.007

26. Budiansky B., Hutchinson J. W., Evans A. G. (1986): Matrix fracture in fiber-reinforced ceramics. Journal of the Mechanics and Physics of Solids, 34(2), 167-189. doi: 10.1016/0022-5096(86)90035-9

27. Curtin W. A. (1991): Theory of mechanical properties of ceramic-matrix composites. Journal of the American Ceramic Society, 74(11), 2837-2845. doi: 10.1111/j.11512916.1991.tb06852.x

28. Phoenix S. L., Raj R. (1992): Overview no. 100 Scalings in fracture probabilities for a brittle matrix fiber composite. Acta Metallurgica et Materialia, 40(11), 2813-2828. doi: 10.1016/0956-7151(92)90447-M

29. Longbiao L. (2017): Synergistic effects of fiber debonding and fracture on matrix cracking in fiber-reinforced ceramicmatrix composites. Materials Science and Engineering: A, 682, 482-490. doi: 10.1016/j.msea.2016.11.077

30. Li L. B., Song Y. D., Sun Y. C. (2014): Modeling the tensile behavior of unidirectional $\mathrm{C} / \mathrm{SiC}$ ceramic-matrix composites. Mechanics of Composite Materials, 49(6), 659-672. doi: 10.1007/s11029-013-9382-y

31. Li L. B., Song Y. D., Sun Y. C. (2015): Modeling the tensile behavior of cross-ply $\mathrm{C} / \mathrm{SiC}$ ceramic-matrix composites. Mechanics of Composite Materials, 51(3), 359-376. doi: 10.1007/s11029-015-9507-6

32. Zhang S., Gao X., Chen J., Dong H., Song Y. (2016): Strength model of the matrix element in $\mathrm{SiC} / \mathrm{SiC}$ composites. Materials \& Design, 101, 66-71. doi: 10.1016/j. matdes.2016.03.166 